\title{
Las concesiones de servicio público en un contexto liberalizado
}

\author{
José Manuel Sala Arquer
}

Catedrático de Derecho Administrativo Universidad Rey Juan Carlos

\section{EL ACTUAL MODELO ESPAÑOL DE LAS CONCESIONES DE SERVICIOS PÚBLICO}

\section{El debate sobre la subsistencia del servicio público como concepto y como} régimen jurídico.

Hace ya bastantes años, dediqué un primerizo trabajo a los orígenes históricos de la noción de servicio público en España ${ }^{1}$. En él se llegaba a la conclusión de que los primeros tratadistas españoles carecían de una idea clara respecto de lo que fuera el servicio público; este concepto fue formándose en España no tanto como una noción precisa, elaborada doctrinalmente, cuanto como un conjunto de reglas jurídicas -no codificadas, ni establecidas con carácter general-, que se podían extraer de distintas leyes sectoriales. En esos momentos iniciales, en torno a mediados del s. XIX, aparece un régimen jurídico peculiar, que se aplica a una serie de actividades que requieren una prestación ininterrumpida, y cuyo máximo exponente son las concesiones de ferrocarriles. Ese régimen jurídico tampoco era uniforme: así, la quiebra de la compañía de servicios públicos, regulada en el Código de Comercio de 1885 -para ser exactos, "compañías y empresas de ferrocarriles y demás obras de servicio público general"- nunca se aplicó a otros servicios distintos de los ferroviarios, como los de abastecimiento de agua, gas o electricidad, cuyas quiebras siguieron el procedimiento ordinario ${ }^{2}$.

* Ponencia presentada en el SEXTO COLOQUIO LUSO-ESPAÑOL DE DERECHO ADMINISTRATIVO. Lisboa, 3 y 4 de diciembre de 2004.

${ }^{1}$ SALA ARQUER: La noción jurídica de servicio público en España. Notas para un estudio sobre su orígenes históricos. Revue Internationale de Sciences Administratives, nº 3 (1976).

2 VILLAR PALASÍ: Prólogo a "La cláusula de progreso en los servicios públicos", de J.L. Meilan, Madrid 1968. 
A la vuelta de siglo y medio, parece que volvemos al punto de partida. Muchos de esos servicios -agua, gas, electricidad- que en sus comienzos disfrutaban de una absoluta libertad para su ejercicio, y que posteriormente pasaron por una reglamentación cada vez más intensa, hasta terminar en su "publicatio" o declaración de servicio público, han seguido el camino de vuelta, y se encuentran en diferentes grados de liberalización; junto a estos supuestos, conviven distintos ejemplos de servicios públicos clásicos, en los que se aplica ese conjunto de reglas y principios característicos: continuidad, regularidad, igualdad, adaptación, potestad tarifaria, etc.

Esta situación ha propiciado en España el conocido debate sobre la supuesta abolición de la noción del servicio público, y el peligro que ésta puede suponer para la calidad de esas actividades prestacionales ${ }^{3}$. En un principio, los defensores de "lo público" comenzaron señalando como culpable de este deterioro al concepto -surgido en el Derecho comunitario- de "servicios de interés económico general ${ }^{4}$. En esto, los críticos españoles coinciden con la actitud general de recelo surgida en Francia a comienzos de los años noventa, cuando numerosos autores vieron en este concepto -y en su derivado, el "servicio universal"- una amenaza para el concepto tradicional del "service public a la française" ${ }^{" 5}$ (en expresión acuñada por el entonces primer ministro, Alain Juppé). Sin embargo, aquí acaba el paralelismo, por la sencilla razón de que en Francia, más allá de una legislación anti-corrupción que permitió una mínima transparencia en la "delegación" de servicios públicos (ley de 29 de enero de 1993), y la liberalización del tráfico aéreo y las telecomunicaciones, lo que se produjo fue el mantenimiento del modelo tradicional en la mayoría de los servicios de red y el efectivo bloqueo, en el Consejo de Ministros, de cualquier intento de la Comisión Europea por aprobar una Directiva sobre concesiones de servicios públicos. Ese modelo, por otra parte, concedía a la Administración poderes muy superiores a los que le reconoce la legislación española, especialmente en cuanto a la amplia discrecionalidad en la adjudicación de las concesiones.

\footnotetext{
${ }^{3}$ Un exponente último en el número monográfico de la Revista de Derecho de la Unión Europea, dedicado a los "servicios públicos, privatizaciones y liberalizaciones en la Unión Europea" (RDUE no 7 [2004]).

${ }^{4}$ Vid. un intento de interpretar el art. 90.2 del Tratado a la luz del "Service public" en GONZÁLEZ VARAS, S.: El Derecho comunitario ante el servicio público y la competencia”, Gaceta Jurídica de la CE, junio 1997.

${ }^{5}$ Es ilustrativo el número especial de "Actualité Juridique-Droit administratif" dedicado a los servicios de interés económico general (Vid. AJDA, , no 3 [1996]), con estudios como el de Marc
} 
Por el contrario, en España entre 1996 y 2004 se ha producido una liberalización -mejor o peor, según los casos- de estos servicios. Por tanto, la crítica más reciente, en nuestro caso, ya no se dirige contra el artículo 86 del Tratado (antes 90), sino directamente contra la política de liberalizaciones seguida en estos últimos años y, sobre todo contra la conclusión teórica según la cual esa legislación habría dado lugar a un eclipse de la noción tradicional de servicio público. Tanto el Derecho comunitario como la Constitución -se dicepermiten "la continuidad de la tradicional noción de servicio público objetivo o, mejor, de servicio público funcional... como equivalente a prestación de determinadas características -regularidad, calidad, solidaridad, acceso en igualdad, precio asequible, etc.- requerida por el interés general con independencia del sujeto que la desarrolle" ${ }^{6}$. Crítica muy a tener en cuenta, aunque sólo sea porque coincide con un cambio de mayoría política que, hasta ahora, parece orientarse a una revisión de lo hecho durante la etapa anterior.

Como pasa tantas veces, hay en estos debates una fuerte carga ideológica, que frecuentemente se traduce en un cierto nominalismo. Quienes postulan la reformulación del concepto de servicio público, en el marco de las recientes políticas liberalizadoras, no tienen inconveniente en afirmar que el servicio público es la excepción a la regla general de la libertad de mercado, o que "debemos ir a unos servicios públicos reducidos en número y extensión"; ; sus críticos hablan del "nuevo paradigma conservador", al que acusan de sacralizar las técnicas e instituciones jurídicas del "statu quo", frente a las innovaciones del derecho público -entre las que parece situarse ahora el servicio público, surgido por cierto en España a mediados del s. XIX- ${ }^{8}$. A la vista de estas y otras afirmaciones, uno no sabe si acudir a la famosa receta del juez Holmes, que aconsejaba "someter a un baño de ácido cínico" algunos grandilocuentes conceptos jurídicos, o incluso preconizar una -por otra parte imposible- kelseniana teoría pura del Derecho público, liberada de adherencias políticas de

DEBENE y Olivier RAYMUNDIE: "Sur le service universal: renouveau du service public ou nouvelle mystification?"; también son reveladoras las Actas del coloquio de 14 y 15 de noviembre de 1996, celebrado en el Senado francés, sobre la "gestión delegada del servicio público", publicadas como suplemento de la Revue Française de Droit administratif, no 3 (1997).

${ }^{6}$ PAREJO, L: "Servicios públicos y servicios de interés general: la renovada actualidad de los primeros”, RDUE no 7 (2004), p. $64-67$.

${ }^{7}$ DE LA CUÉTARA, J.M.: "Perspectivas para los servicios públicos españoles para la década de los noventa", en el vol. colectivo El nuevo servicio público, Madrid 1997, p. 58 y ss.

${ }^{8}$ LINDE PANIAGUA, E.: "La retirada del Estado de la Sociedad: privatizaciones y liberalización de servicios públicos", RDUE no 7 (2004), p. 31 y ss. 
diverso signo. El debate sobre el servicio público se está convirtiendo, en nuestro país, en un debate sobre conceptos ${ }^{9}$;

Ahora bien, es evidente que el debate sobre el servicio público tiene importantes consecuencias para el tema de esta Ponencia, que no es otro que el de las concesiones de servicios públicos.

Recordemos brevemente, antes de seguir adelante, las notas fundamentales que, en nuestro Derecho, caracterizan el régimen jurídico concesional:

a) Con carácter previo a la adjudicación de la concesión, "deberá haberse determinado su régimen jurídico básico que atribuya las competencias administrativas, que determine el alcance de las prestaciones a favor de los administrados y que declare expresamente que la actividad de que se trata queda asumida por la Administración respectiva como propia de la misma". (art. 155.2 del Texto Refundido de la Ley de Contratos de las Administraciones Públicas, aprobado por Real Decreto Legislativo 2/2000, de 16 de junio). Aquí se contiene y positiviza la nota tradicional de la "publicatio" de la actividad, resaltándose la creación de un ámbito de supremacía de la Administración y de sujeción especial del concesionario a la Administración (el apartado 3 de este mismo precepto subraya que "en todo caso, la Administración conservará los poderes de policía necesarios para asegurar la buena marcha de los servicios de que se trate").

b) Pero al mismo tiempo, la concesión es también una empresa productiva, con sus propias exigencias, su autonomía y su propio estilo de gestión (industrial o comercial). La Administración debe respetar esas reglas de juego, propias de toda empresa que necesita equilibrar sus balances, seleccionar sus directivos por sus condiciones profesionales (no por otros criterios), obtener el beneficio necesario para remunerar el capital invertido, generar una cierta capacidad de autofinanciación, etc. Este tema de la autonomía empresarial es y ha sido siempre uno de los grandes ausentes de la regulación de la Ley de Contratos de las Administraciones Públicas, en sus sucesivas versiones.

\footnotetext{
${ }^{9}$ GONZÁLEZ-VARAS dedica un trabajo a analizar una serie de "opciones conceptuales" que, a su juicio, se abren para definir estos servicios liberalizados: "mercados de interés general", "servicios de interés general", "sectores", "sectores de interés general", "sectores estratégicos", "sectores liberalizados”... (GONZÁLEZ-VARAS, S.: “¿Del servicio público a los mercados de interés general?” Cuadernos de Derecho Público 12 (2001), p. 63-78).
} 
c) La concesión es, económicamente, un capital privado adelantado que se pone a disposición de la colectividad, con carácter temporal y con un régimen de amortización financiera o de capital a lo largo de los años de gestión ${ }^{10}$.

d) El concesionario está obligado a prestar el servicio en régimen de continuidad (mantenerlo permanentemente, salvo caso de fuerza mayor) y regularidad (prestarlo en las condiciones y con las características técnicas establecidas). Esto exige que el servicio esté sobreequipado y tenga una reserva de capacidad no empleada, determinada por la Administración e incluida en el cálculo de costes del servicio. La continuidad, a la que se refiere el art. 161 a) del Texto Refundido como una obligación del concesionario, es algo más que eso; es un auténtico principio estructural del servicio público, que despliega sus efectos en muchos otros aspectos del régimen jurídico de la concesión: reversión, rescate, poderes de intervención y régimen especial de embargos y suspensiones de $\operatorname{pagos}^{11}$.

e) Desde el punto de vista de los derechos del concesionario, el principio esencial que preside la concesión es el del equilibrio financiero de la explotación, proclamado por toda la legislación administrativa española; la jurisprudencia del T.S ha llegado a afirmar que este principio, expresión de la colaboración del concesionario con la Administración, desplaza en este ámbito al tradicional del "riesgo y ventura", propio de los contratos administrativos y que el Texto Refundido sigue proclamando en su art. 156 a).

Este es, a grandes rasgos, el modelo concesional asentado en nuestro Derecho para aquellos casos en que existe una efectiva y auténtica asunción de la actividad de que se trate por parte de la Administración.

Pues bien, la concesión, modo de gestión indirecta, requiere la previa declaración de servicio público de una determinada actividad; pero también precisa que, en aquellos ámbitos donde esa "publicatio" no se haya producido, no existan situaciones ambiguas, en las que, de forma encubierta, se someta a quienes ejercen libremente una actividad -por muy reglamentada que pueda

\footnotetext{
${ }^{10}$ Un completo estudio de este tema, desde el punto de vista fiscal y contable, en ANDRÉS AUCEJO, Eva: "La amortización de los activos revertibles a la Administración", Impuestos, II (1999), p. 1129-1162. En el derecho francés, y con especial referencia a la Ley de 29 de enero de 1993, vid. LINDITCH, F: "Recherches sur la place de l'amortissement en droit administratif", Actualité Juridique-Droit Administratif, no 1 (1996), p. 100-110.
}

${ }^{11}$ Vid. SALA ARQUER: El principio de continuidad de los servicios públicos, Madrid 1977. 
estar- a un estatuto jurídico similar al de un concesionario, con las cargas y deberes de éste, pero muchas veces sin sus derechos.

El concepto de servicio público objetivo o funcional, tal como se viene formulando por algunos autores, presenta a mi juicio este peligro. En otro lugar he señalado que la noción de "servicio público objetivo" supone la confusión entre dos conceptos -y dos regímenes jurídicos- perfectamente diferenciados y asentados desde hace años en España, como son el servicio público y la actividad reglamentada, que no hay necesidad alguna de asimilar. Los ejemplos que muchas veces se citan de "servicios públicos objetivos o funcionales" son, en gran medida, situaciones transitorias que con el tiempo terminan decantándose hacia uno u otro modelo: o bien la reglamentación da paso a la "publicatio" de la actividad, o bien se produce la total y definitiva liberalización de esta ${ }^{12}$. Así se advierte en casos como el de las telecomunicaciones, donde la Ley 11/1998, de 24 de abril, todavía regulaba unos títulos habilitantes -licencias individuales y autorizaciones generales- con claras resonancias concesionales (interpretación unilateral de sus cláusulas por la CMT, continuas remisiones a la regulación del contrato de gestión de servicios públicos, etc.), lo que llevó a algún autor a afirmar que la Ley General de Telecomunicaciones no hace sino extrapolar "el régimen de la gestión indirecta de los servicios públicos de titularidad administrativa, como prueba de que la "neorregulación" no ha sido capaz de obviar en el plano técnico-jurídico la pervivencia del viejo modelo de servicio público y de la técnica concesional"13. Como tantas veces, una palabra del legislador (en este caso, a través de la nueva Ley 23/2003, de 3 de noviembre, General de Telecomunicaciones), ha dejado sin contenido los comentarios doctrinales: desaparecen las figuras de las autorizaciones y licencias como títulos habilitantes (que se sustituyen por la simple notificación a la CMT) y con ellos las remisiones al marco del contrato de gestión de servicios públicos. Con ello se clarifica un ámbito que, definitivamente, se aleja del modelo concesional y se inscribe en el de los servicios de interés económico general en régimen de libre competencia ${ }^{14}$. Bien entendido

${ }^{12}$ SALA ARQUER: La liberalización del monopolio de petróleos en España, Madrid 1995, p. 30.

${ }^{13}$ SOUVIRON MORENILLA, J.L.: El proceso de liberalización y la nueva regulación de las telecomunicaciones, Granada 1999, p. 324.

${ }^{14}$ Una rigurosa clarificación y deslinde de nociones a que a menudo se confunden en relación con esta materia, en MARTÍNEZ LÓPEZ-MUÑIZ, J.L: "Servicio público, Servicio Universal y "Obligación de servicio público en la perspectiva del Derecho comunitario: los servicios esenciales y sus regímenes alternativos", en el vol. colectivo Os caminhos da privatizaçao da Administraçao Pública, Coimbra 2001, p. 250 y ss. 
que este término comunitario define una realidad tan extensa y variopinta, que no es en modo alguno indicativo de un régimen jurídico uniforme ${ }^{15}$.

¿Y qué decir del viejo paradigma de las concesiones ferroviarias, que según veíamos al principio fueron en el s. XIX el modelo inspirador de la categoría misma de la concesión de servicio público? Lo que regula la nueva Ley 39/2003, de 17 de noviembre, del Sector Ferroviario, es la "licencia de empresa ferroviaria", que habilita para la prestación de los servicios de transporte ferroviario de viajeros o de mercancías, única para toda la Red Ferroviaria de Interés General, dentro de la capacidad de infraestructura que se le haya adjudicado por el administrador de la misma. Todo ello en el ámbito de un "mercado de las empresas ferroviarias", en el que los servicios se prestan en régimen de competencia. También aquí se diferencia claramente este ámbito del que corresponde a los "servicios ferroviarios de interés público", en el que la actividad requiere previa autorización, que se adjudica a través del correspondiente procedimiento de licitación pública ${ }^{16}$.

No hay, -o si las hay, cada vez son menos-, zonas fronterizas o confusas entre la concesión de servicio público y las actividades reglamentadas. Conviene, por tanto, comenzar por una delimitación negativa de la concesión, porque esa "publicatio" encubierta de actividades de que antes hablaba no es una elucubración teórica, sino una realidad de la que cabe dar cuenta con algunos ejemplos tomados del Derecho positivo, a los que enseguida me referiré.

\section{2. ¿La vuelta de las "concesiones industriales"?}

Las concesiones industriales fueron una categoría lanzada a la circulación por el profesor VILLAR PALASÍ, en los años cincuenta, en el contexto de una

\footnotetext{
15 Basta repasar los diferentes supuestos calificados por la jurisprudencia comunitaria como "servicios de interés económico general", para comprobar que bajo este supraconcepto conviven realidades que, en nuestro país, son ejemplos de concesiones de servicio público -televisión, transporte por carretera, abastecimiento de agua- que son servicios liberalizados (Vid. sobre esta cuestión DE QUADROS, F.: "Serviço Público e Direito Comunitario”, en Os caminhos... cit., p. 279-299.

${ }^{16}$ Hay que precisar que, a pesar de esta declaración de apertura a la competencia, subsisten algunos servicios en los que se mantiene la "publicatio", y respecto de los cuales -como observa CARLON RUIZ- las licencias presentan un contenido "cuasi-concesional". También aquí se advierte la subsistencia de un régimen transitorio, que terminará decantándose hacia la liberalización y la apertura a la competencia, momento en el que desaparecerá ese aspecto "cuasi-concesional”. (Vid. CARLON RUIZ, M: "El régimen jurídico del sector ferroviario” en el vol. colectivo Transportes y competencia, Madrid 2004, p. 390 y ss).
} 
economía de postguerra, en la que el Estado era el principal -por no decir único- motor de la actividad industrial ${ }^{17}$. En el planteamiento del autor citado, la concesión industrial se concebía como la explicación de una serie de supuestos que, sin poder subsumirse bajo la noción de servicio público, requerían títulos habilitantes para el ejercicio de una actividad industrial reservada al Estado.

A pesar de que ya en su momento esta idea no fue compartida por la mayoría de la doctrina, es curioso comprobar que ha seguido siendo utilizada por el Tribunal Supremo, incluso mucho después de aprobada la Constitución de 1978, cuyo artículo 38 reconoce "la libertad de empresa en el marco de la economía de mercado". Básicamente el concepto se ha aplicado en el ámbito de los monopolios fiscales, donde el ejercicio de actividades incluidas en el ámbito objetivo del monopolio podían ser realizadas por empresas públicas o privadas previa "concesión" del Gobierno. Como muchas de estas actividades resultaba difícil encajarlas en la concepción del servicio público, el Tribunal Supremo desempolvó la vieja idea de las concesiones industriales: así, en la S. de 1 de junio de 2001, relativa a las importaciones de gas natural por ENAGAS, se califica como concesiones industriales las actividades de refino, petroquímicas, gas butano, propano, y gas natural (en el mismo sentido, S.S. de 28 de marzo de 1988, 29 de mayo de 1995 y 24 de septiembre de 1996). Y la S. de 30 de noviembre de 1999 no tiene más remedio que acudir al concepto de concesión industrial para calificar la actividad de suministro, explotación y distribución de boletos de juego, afirmando que dicha actividad

“... Supone la conversión formal de una concreta actividad en servicio público con objeto de excluir aquella del sistema de libertad industrial para constituir un monopolio administrativo desde el que, mediante la técnica de la concesión, se otorgan derechos, en este caso para la explotación, suministro y distribución de boletos a empresas privadas en atención a los fines que se pretende, por lo que no se trata de la renovación, mediante la técnica de la autorización, de limitaciones impuestas al ejercicio de actividades privadas, sino ante la concesión para el ejercicio para una actividad reservada en exclusiva al sector público, aunque no se trate de un servicio público ni de la gestión de éste "stricto sensu" sino de lo que podría denominarse una concesión industrial con un carácter estable y precios determinados por la Administración..."

En la actualidad sólo subsiste en España, como monopolio fiscal, el de loterías, a mi juicio sin ninguna base constitucional, como he estudiado en otro

17 VILLAR PALASí: "Concesiones administrativas", en Nueva Enciclopedia Jurídica, t. IV, (1952), p. 693. Vid. también, de este autor, La actividad industrial de Estado, Madrid 1964. 
lugar ${ }^{18}$. Sin embargo, cada vez que la Administración utiliza los títulos habilitantes para intervenir o controlar el ejercicio de una actividad libre, como si ésta estuviese reservada al sector público, puede decirse que reaparece, de forma encubierta, el esquema de la concesión industrial.

Esto ocurre, a mi juicio, con la regulación prevista en algunas leyes autonómicas sobre licencias para llevar a cabo obras o instalaciones industriales en suelo no urbanizable. Así, la Ley de urbanismo de Andalucía, de 17 de diciembre de 2002, establece que "cuando la ordenación urbanística otorgue la posibilidad de llevar a cabo en el suelo clasificado como no urbanizable actos de edificación, construcción, obras o instalaciones no vinculados a la explotación agrícola, pecuaria, forestal o análoga, el propietario podrá materializar éstos en las condiciones determinadas por dicha ordenación y por la aprobación del pertinente Plan Especial o Proyecto de Actuación y, en su caso, licencia. Estos actos tendrán una duración limitada aunque renovable, no inferior en ningún caso al tiempo que sea indispensable para la amortización de la inversión que requiera su materialización". En sentido similar, la Ley extremeña de suelo y ordenación territorial, de 14 de diciembre de 2001, establece que las licencias se otorgarán, en estos casos, "por plazo determinado fijado en función del tiempo preciso para la amortización de la inversión inicial", si bien "el plazo de vigencia de la licencia podrá ser prorrogado expresa y sucesivamente, siempre antes del vencimiento del que estuviera corriendo. La primera prórroga no podrá exceder de diez años y las sucesivas no podrán superar, cada una de ellas, los cinco años".

Esto quiere decir que si una empresa pretende, por ejemplo, instalar una central eléctrica de ciclo combinado en suelo no urbanizable común -lo que, en principio, está permitido por la Ley- debe solicitar, además de la autorización regulada en la Ley del Sector Eléctrico, una licencia municipal que se le concede por el tiempo que tarde en amortizar la inversión, como si de una concesión se tratara; nada se dice de los criterios que se seguirán para otorgar las sucesivas prórrogas por parte del Ayuntamiento en cuestión, ni de las condiciones a que deberán someterse los interesados para obtenerlas: en todo caso, el transcurso del plazo sin lograr la prórroga determina la caducidad de la licencia y el consiguiente cese de la actividad, justo cuando ésta empieza a ser rentable, lo cual ya da una idea del grado de sumisión que puede lograrse a través de este sistema.

${ }^{18}$ SALA ARQUER: "Liberalización del monopolio de loterías y competencias sobre el juego", REDA 120 (2003), p. 519. 
Algo parecido sucedió con las leyes sobre farmacias de Castilla-La Mancha, Extremadura o Galicia, que llevaron a cabo una regulación de la oficina de farmacia cercana al régimen concesional, estableciendo la intransmisibilidad de las de nueva concesión, y decretando la caducidad de la autorización administrativa en caso de jubilación del farmacéutico. Las farmacias se declaraban "servicios de interés público", lo que abría la puerta a un régimen jurídico cuasi-concesional, en el que la autorización se otorga por concurso público, y la Administración asume importantes poderes en materia de horarios mínimos, turnos de urgencia, turnos vacacionales y cierres temporales. Aunque el Tribunal Constitucional rectificó en parte esta regulación -SSTC 109/2003, de 5 de junio, y 152/2003, de 17 de julio- la verdad es que en esos territorios subsiste un modelo farmacéutico cercano al concesional, muy distinto del vigente en otras Comunidades Autónomas.

Naturalmente, nadie niega la potestad del Estado, o de las Comunidades Autónomas, para declarar como servicio público una determinada actividad, dentro de lo que la Constitución califica como "servicios esenciales". Ahora bien, lo que a mi juicio debe exigirse es que, en tal caso, esa declaración se lleve a cabo formalmente y asumiendo el coste -político y económico- que conlleva. Lo que no cabe es la "publicatio" encubierta, en la que los particulares afectados se encuentran de pronto colocados en una situación de sujeción especial, pero privados de los importantes derechos que la Ley garantiza a todo concesionario. La concepción del servicio público objetivo es, en el fondo, una construcción dogmática muy cómoda para el poder público -le permite intervenir salvando las apariencias de la liberalización- pero muy peligrosa para las garantías de los interesados.

\section{El estatuto jurídico de la empresa concesionaria y el de la empresa presta- dora de servicios liberalizados.}

La tesis del resurgir del servicio público ${ }^{19}$, entendido como una única realidad, que se puede articular en una vertiente funcional -el "servicio público objetivo"- y otra orgánica -el servicio público en régimen de reserva o "publicatio"- no parece muy acorde con la distinta posición jurídica -ante la Administración y ante terceros- propia de una empresa concesionaria y de una empresa de servicios liberalizados.

19 Término utilizado en ocasiones; vid. CASSAGNE, J.C: "El resurgimiento del servicio público y su adaptación en los sistemas de economía de mercado", RAP 140 (1996), p. 95 y ss. 
El estatuto jurídico del concesionario se nos presenta como un conjunto de derechos y obligaciones consolidado, regulado de forma sistemática por una Ley general, que además tiene el carácter de básica; en cambio, no existe en nuestro Derecho positivo una norma que haga lo propio con la figura del gestor de servicios liberalizados. Cada sector tiene su propia regulación, y los poderes de la Administración reguladora varían notablemente según la actividad de que se trate, sencillamente porque en unos casos la liberalización está más avanzada que en otros. Este es un dato del que conviene partir, para no repetir el error de construir la categoría de la empresa prestadora de servicios liberalizados a partir del modelo de un concreto sector (por ejemplo, el eléctrico).

Dicho esto, y sin negar que unos y otros pueden tener en común principios generales como el de continuidad, regularidad, igualdad, adaptación, etc., lo que a mi juicio introduce una profunda diferencia entre ambos modelos es la traducción de esos principios a un concreto régimen jurídico:

\section{A) "Publicatio" frente a competencia.}

El régimen concesional supone, como regla general, la exclusión de la competencia: el monopolio "de iure" del Estado se transforma en un monopolio "de facto" de los distintos concesionarios, que se reparten el mercado: las zonas de suministro, las líneas de transporte, etc ${ }^{20}$. La liberalización supone precisamente suprimir esos privilegios de exclusiva, levantando la reserva formal que en su día se efectuó al sector público, y abriendo la actividad a la libre concurrencia. Es cierto que en este segundo caso la Administración puede, en algunos supuestos, conceder "derechos especiales o exclusivos": pero estos derechos ya no se entienden -como se definían por la Directiva 93/38/CEE, sobre sectores especiales- como una "reserva de actividad", sino como una "limitación" ("limitar a una o más entidades el ejercicio de una actividad"), que afecte "sustancialmente a la capacidad de las demás entidades de ejercer dicha actividad" (art. 2.3 de la Directiva 2004/17/CE del Parlamento Europeo y del Consejo, de 31 de marzo de 2004, sobre la coordinación de los procedimientos de adjudicación de contratos en los sectores del agua, de la energía, de los transporte y de los servicios postales). Por lo demás, cuan-

${ }^{20}$ Como observan LÓPEZ DE CASTRO-ARIÑO, "en estos casos, en los que rige la exclusividad de la prestación (el no mercado, sea con gestión pública o privada), la única competencia que puede establecerse es en el momento de adjudicación del correspondiente contrato de adjudicación del servicio público, usualmente la concesión administrativa a través de licitaciones públicas" (LÓPEZ DE CASTRO-ARIÑO: La competencia en los sectores regulados, 2oㅡ., Madrid 2003, p. 286). 
do esto ocurra, es evidente que nos encontramos ante una realidad sustancialmente idéntica a una concesión, y lo que habrá que plantearse es si su régimen jurídico incluye las garantías suficientes para el interés público y para la empresa beneficiada por un derecho exclusivo o especial.

B) Forma contractual frente a acto unilateral.

Las concesiones de servicio público adoptan en España la forma jurídica del contrato administrativo, con todo lo que ello supone desde el punto de vista de la presencia del poder público en el seno de la relación jurídica. En el caso de los servicios liberalizados, ya hemos visto que en algún caso desaparece incluso la figura del título administrativo habilitante -caso de las telecomunicaciones-; en otros, el título consiste en una autorización que recae sobre la instalación, pero no sobre la actividad, como ocurre en la Ley del Sector Eléctrico, distinguiéndose unas autorizaciones regladas (instalaciones de producción) de las discrecionales (distribución y suministro) ${ }^{21}$. Como regla general, cuando subsiste la exigencia de títulos habilitantes, éstos no se someten a licitación -la Ley del Sector Eléctrico eliminó la figura del concurso, prevista por la anterior LOSEN-, y se otorgan por tiempo indefinido. Una excepción la encontramos en los servicios ferroviarios declarados de interés público, en el que la autorización se otorga a través de un procedimiento de licitación pública; de quedar éste desierto, el Ministerio de Fomento puede imponer su prestación como obligación de servicio público; esta singularidad se explica por el deseo del legislador de anticipar la futura regulación comunitaria contenida en la Propuesta de Reglamento (COM [2002] 107 final) a que luego nos referiremos.

C) Principio de continuidad y poderes de la Administración.-

El principio de continuidad supone, para el concesionario de servicios públicos, la sumisión a un conjunto de potestades administrativas. Es cierto que la normativa mercantil sobre quiebras y suspensiones de pagos de compañías de servicios públicos, si bien nunca ha sido expresamente derogada, resulta hoy inaplicable en la medida en que estas situaciones son determi-

${ }^{21}$ Vid. ARIÑO-LÓPEZ DE CASTRO: El sistema eléctrico español: Regulación y competencia, Madrid 1998, p. 593 y ss. A juicio de DE LA CRUZ FERRER, el acto de autorización tiene en este caso un contenido complejo, en el que se confunden una autorización de instalación, otra de actividad -sobre las condiciones en que se realizará la explotación de las instalaciones-, y una licencia subjetiva, relativa a los requisitos del solicitante (DE LA CRUZ FERRER: La liberalización de los servicios públicos y el sector eléctrico, Madrid 1999, p. 416). 
nantes de la resolución del contrato ${ }^{22}$; sin embargo la forma contractual pública que revisten las concesiones determina que les sea de aplicación lo dispuesto en el art. 112.7 del Texto Refundido de la LCAP, según el cual "en la quita y espera y en la suspensión de pagos la Administración continuará el contrato si el contratista prestare las garantías suficientes a juicio de aquella para la ejecución del mismo”.

Conectada con lo anterior, pero ya de forma específica en la regulación de la concesión, está la figura del rescate, que no es sino la reversión anticipada por acto unilateral y discrecional de la Administración, por motivos de interés público mediante la correspondiente indemnización. Subsiste, en todo caso, el servicio público, que debe continuar; el artículo 168.2 LCAP impone que, en este caso, la continuación del servicio se lleve a cabo por gestión directa: si bien conviene notar que este precepto no tiene carácter básico, y la legislación sectorial estatal prevé a veces soluciones distintas, como ocurre con la concesión de transporte regular de viajeros por carretera, art. 84.1 de la Ley 16/1987, de 30 de julio.

Concesiones de servicios públicos y empresas de servicios liberalizados tienen en común la figura de la intervención de la empresa por parte de la Administración (que en el caso de las primeras se denomina tradicionalmente "secuestro" de la concesión). Ahora bien, la figura de la intervención está prevista en el art. 128.2 CE respecto de cualquier empresa "cuando así lo exigiere el interés general”. De hecho, el legislador ha regulado esta posibilidad también para las entidades financieras (bancos, cajas de ahorros, sociedades y agencias de valores) y para las compañías de seguros ${ }^{23}$. La comparación entre el régimen de la intervención de empresas concesionarias y el de las empresas de servicios liberalizados parece indicar que en las primeras se concibe como una "última ratio" para casos-límite (incumplimiento del contratista del que se derive perturbación grave y no reparable por otros medios del servicio público, art 166 LCAP), mientras que en las segundas el panorama es muy variado: así, en el caso de la Ley General de Telecomunicaciones, el art. 4.5 prevé -con

\footnotetext{
22 Vid. sobre este punto MESTRE DELGADO, J.F.: La extinción de la concesión de servicio público, Madrid 1992, p. 113. Hoy tras la Ley 22/2003, de 9 de junio, concursal, estas menciones deben entenderse hechas al concurso de acreedores; la Disposición Final 13 de esta Ley ha modificado distintos preceptos de la LCAP.

23 GAMERO CASADO, señala que la facultad de intervención no responde a los poderes que se confieren a la Administración en el marco del régimen propio de los servicios públicos (GAMERO CASADO, E: La intervención de empresas, Madrid, 1996 p. 173).
} 
carácter excepcional y transitorio- en caso de incumplimiento de las obligaciones de servicio público, la posibilidad de la asunción de la gestión directa de esos servicios (y no otros). En el caso de las Ley de Hidrocarburos, su Disposición Adicional décima establece un elenco de supuestos que son causa de intervención "de la correspondiente empresa", que van desde la suspensión de pagos o quiebra, hasta la gestión irregular de la actividad que pueda dar lugar a la paralización, o la grave y reiterada falta de mantenimiento adecuado de las instalaciones que ponga en peligro la seguridad de las mismas. Estos supuestos, de tipo más bien "preventivo", se reiteran en la Ley del Sector Eléctrico, si bien el caso de la gestión irregular se contempla como intervención "a posteriori", ya que se requiere que se produzca "interrupción del suministro" 24 .

En cambio, la Ley 24/1998, de 13 de julio, reguladora del Servicio Postal Universal y de liberalización de los servicios postales, que establece la obligación del prestador del servicio postal universal de "no interrumpir ni suspender el servicio, salvo caso de fuerza mayor" (art. 16.4 d) se limita a sancionar esta obligación con la responsabilidad económica salvo caso de fuerza mayor (art. 21.1) y con la tipificación como infracción muy grave del "incumplimiento de las condiciones establecidas para la prestación del servicio postal universal que haga que este resulte gravemente comprometido".

Finalmente, la Ley 29/2003, de 17 de noviembre, del Sector Ferroviario, dentro del Capítulo dedicado a los servicios ferroviarios declarados de interés público -pero sin aclarar si se refiere sólo a ellos o también a otros- prevé la posibilidad de la asunción de la gestión directa, con carácter excepcional o transitorio, para garantizar la seguridad pública y la defensa nacional (art. 54.1); ya con referencia expresa a los servicios de interés público, el apartado 3 de este artículo dispone que en caso de interrupción, o de prestación que no garantice la seguridad de las personas, el Ministerio de Fomento "adoptará todas las medidas necesarias para garantizar su correcta prestación”.

D) Cláusula de progreso frente a libertad de empresa.-

La cláusula de progreso en las concesiones de servicio público es, como señala MEILAN en su fundamental monografía sobre el tema, una solución de compromiso, que trata de responder al conflicto entre el interés público y la

\footnotetext{
${ }^{24}$ Vid. un análisis de estos supuestos, desde la óptica de las situaciones de crisis económico-financiera de estas empresas, en DEL GUAYO CASTIELLA: Sector público empresarial e instituciones para concursales, Madrid 2004, p. 214 y ss.
} 
situación jurídicamente protegida del concesionario, en los términos del "contractus lex" $" 25$. Nace muy ligada a los privilegios de exclusiva, ante los que actúa como un contrapeso. Y hoy puede entenderse recogida, de forma más o menos explícita, en multitud de preceptos que regulan la potestad de la Administración de introducir "modificaciones en las condiciones de prestación no previstas en el título concesional", como establece el art. 75.3 LOTT, o "la variación en la calidad, cantidad, tiempo o lugar de las prestaciones en que el servicio consista" (art. 128.1 RS).

Ahora bien, en los servicios liberalizados esta obligación de adaptación o adaptabilidad, como se denomina en la doctrina francesa, requiere alguna precisión adicional. Es cierto que distintas leyes sectoriales recogen la obligación de las empresas de prestar desarrollar su actividad con los "niveles de calidad que se determinen" (art. 41.1b) de la Ley del Sector Eléctrico, o art. 68 a) de la Ley de Hirdrocarburos). Pero en primer lugar, esta exigencia se refiere a instalaciones concretas, objeto de una autorización singular, y a mi juicio tiene que ver más con el adecuado mantenimiento de redes, instalaciones o canalizaciones, que con una auténtica "potestas variandi", que permita a la Administración imponer -con la correspondiente indemnización- la incorporación de auténticos avances tecnológicos, que pueden suponer una importantísima inversión. Ese tipo de decisión, en un servicio liberalizado, entra dentro del ámbito de la libertad de empresa. En segundo lugar, en un contexto de competencia, será el mercado el que sancione la falta de adaptación al progreso tecnológico. Una empresa eléctrica puede adoptar la decisión de invertir en centrales de tecnología más avanzada y menos contaminantes, como son las de ciclo combinado; otra puede preferir utilizar centrales basadas en el carbón: es evidente que estas decisiones tendrán su consecuencia respecto de los costes de producción, e incluso en cuanto a la valoración de la empresa en Bolsa (así, el hecho de que las instalaciones tengan niveles altos de emisión de $\mathrm{CO}_{2}$ y "consuman" un nivel alto de derechos de emisión, puede determinar -como de hecho ha sucedido- un descenso en la cotización bursátil).

E) El binomio "potestas variandi" -equilibrio financiero.-

Ambas cuestiones aparecen reguladas, sucesivamente, en los apartado 1 y 2 del artículo 163 LCAP.

\footnotetext{
25 MEILAN GIL: La “Cláusula de progreso” en los servicios público, Madrid 1968, p. 24.
} 
El primero establece que "la Administración podrá modificar, por razones de interés público, las características del servicio contratado y las tarifas que han de ser abonadas por los usuarios".

Y el segundo precisa que "cuando las modificaciones afecten al régimen financiero del contrato, la Administración deberá compensar al contratista de manera que se mantenga el equilibrio de los supuestos económicos que fueron considerados como básicos en la adjudicación del contrato"

Este y otros preceptos similares en el ámbito de los servicios públicos locales, han dado lugar a una abundante jurisprudencia, que llega incluso a plantear la compensación de los mayores gastos financieros en que haya podido incurrir el concesionario. Pero en la legislación sectorial sobre servicios liberalizados es inútil buscar una proclamación de este principio. Cuando se impone la prestación del servicio universal, o de otras obligaciones de servicio público, en unos casos se prevé un mecanismo de financiación (así, el Fondo de Compensación del Servicio Postal Universal o del Servicio universal de telecomunicaciones), en otros no se indica nada (como ocurre con la obligación del distribuidor eléctrico de "atender en condiciones de igualdad las demandas de nuevos suministros eléctricos en las zonas que operen" (art. 45.1 LSE), o se habla de modo bastante genérico de que la empresa "será resarcida" (art. 54 de la Ley del Sector Ferroviario). Pero nada se dice respecto del equilibrio financiero del prestador del servicio, ante eventuales modificaciones introducidas posteriormente respecto de unas condiciones que tampoco se fijaron contractualmente, sino que se impusieron unilateralmente, y cuyo coste -normalmente- o se distribuye entre todos los operadores, o bien se considera una "carga justificada" que debe asumir el prestador del servicio ${ }^{(25}$ bis $)$.

\section{Conclusiones sobre el modelo español de la concesión de servicios públicos.}

Más allá de debates semánticos o ideológicos, el análisis del régimen jurídico básico de la concesión de servicios públicos, en su contraste con el de las empresas gestoras de los servicios liberalizados, pone de manifiesto, a mi juicio, lo siguiente:

a) No existe fundamento, en el derecho positivo, para mantener una asimilación o un sustrato común entre el servicio público estricto, que se presta

\footnotetext{
25bis El caso de las llamadas "actividades reguladas", dentro de los sectores liberalizados, constituye a mi juicio uno de esos casos transitorios, en marcha hacia la liberalización, donde están presentes algunos elementos del servicio público (tarifas, principio del coste real) pero no otros (no hay "ius sariandi" de la Administración).
} 
en actividades asumidas como propias por la Administración, y el conjunto de servicios liberalizados, que se pretenden presentar como ejemplos de "servicios públicos objetivos".

b) El estatuto jurídico de la concesión de servicios públicos está claramente definido en la legislación general, y contiene las adecuadas garantías para la empresa concesionaria, que contrapesan los mayores poderes atribuidos a la Administración. Esto no ocurre con la encomienda del servicio universal o con las obligaciones de servicio público, que no siempre son indemnizables, o lo son en parte, y en las que no se afirman claramente los derechos de la empresa frente a eventuales modificaciones impuestas por la Administración.

La consideración de estas empresas que actúan en servicios liberalizados como un "servicio público objetivo", sin tener en cuenta las diferencias de régimen jurídico frente a la concesión, conllevan el peligro de situarlas en un "status" de especial sujeción, sin el contrapeso de las adecuadas garantías: estaríamos, entonces, ante una reaparición de las viejas "concesiones industriales”, de las que ya se advierte algún ejemplo en la legislación autonómica. Esto no quiere decir que no sea deseable -por el contrario, sería muy conveniente- que en el ámbito de la asignación del servicio universal, o de otras obligaciones de servicio público, estén presentes muchos de los principios y garantías del régimen concesional. Creo que esto se echa de menos en la legislación sectorial española, si bien, como luego veremos, puede terminar convirtiéndose en una exigencia derivada del Derecho Comunitario.

c) El régimen concesional estricto, tal como ha quedado definido, cuenta ya con pocos ejemplos en el ámbito estatal ${ }^{26}$ : subsisten las concesiones de televisiones privadas, al amparo de la Ley 37/1988, de 3 de mayo, reguladora de la televisión privada, las concesiones de radiodifusión (onda media), o la concesión de transportes públicos regulares de viajeros de uso general, regulada en la Ley 16/1987, de 30 de julio, de ordenación de transportes terrestres. En el ámbito autonómico pueden aportarse algunos -pero no muchos más- ejemplos: las concesiones de televisiones locales por ondas terrestres, o las concesiones de radiodifusión sonora (FM). Pero el ámbito donde se mantiene sin demasiados cambios la figura de la concesión de servicio público es el local, en el que los ejemplos de servicios concedidos son muy numerosos. Ahora bien, esto no debe llevar a la conclusión de que, en la esfera local, no

\footnotetext{
${ }^{26}$ Me refiero aquí a las concesiones de servicio público en sentido estricto, es decir, sin tomar en cuenta las concesiones de obra pública, que obviamente incluyen una parte -la relativa a la explotación de la obra- que se rige por las reglas de la concesión de servicio público.
} 
existe un concepto estricto de servicio público, al tener tal consideración todos los dirigidos al cumplimiento de los fines de la competencia de las entidades locales ${ }^{27}$. Es cierto que, junto a este "concepto amplio" de servicio público consagrado en el art. 85.1 de la Ley de Régimen Local, ésta regula un servicio esencial reservado por Ley a las entidades locales (art. 86.3). Como observa DE LOS MOZOS “estos servicios locales esenciales y reservados se refieren a las actividades que han resultado publificadas por la Ley básica (en aplicación del art. 128.2 de la Constitución) y que, por ello, han sido sustraídas a la iniciativa privada" ${ }^{28}$. Si la propia Ley contempla la figura de unos servicios "reservados", parece que aquí se da una contraposición con los demás, que entrarían en la categoría del "servicio objetivo".

Ahora bien, toda esta terminología puede resultar engañosa si nos situamos en el punto de vista de la concesión de servicios públicos. En los servicios del artículo 85.1, cabe -como precisa el apartado 2 de este artículo- la gestión de forma directa o indirecta; de tal modo que, en principio, sería posible la adjudicación de una concesión respecto de alguno de estos servicios (siempre que no impliquen ejercicio de autoridad), a pesar de que la Ley no los declara "servicios esenciales" ni efectúa reserva alguna. Cuando el art. 86 efectúa expresamente esa reserva, en su apartado 3, previamente indica que el Pleno de la Corporación "determinará la forma concreta de gestión del servicio" (art. 86, ap. 2). Aquí parece que esa reserva expresa "ex lege" sólo añade la posibilidad de prestar el servicio en régimen de monopolio, si así se aprueba por el órgano de gobierno de la Comunidad Autónoma. De tal modo que al final no queda claro, en esta confusa regulación, cuándo procede la gestión indirecta de los servicios "no esenciales", y qué diferencia existe con los "esenciales", supuesto que en ambos casos es posible la adjudicación de concesiones que concurran con terceros en régimen de libre competencia.

La aprobación de la Ley de Contratos de las Administraciones Públicas, de aplicación directa a las entidades locales, ha venido a clarificar este panorama. De una interpretación conjunta de ambas normas, creo que puede concluirse lo siguiente:

- Para que una entidad local adjudique una concesión, no basta que la actividad esté genéricamente declarada como de competencia local: dada la amplitud

\footnotetext{
${ }^{27}$ Es la tesis que mantiene PAREJO ALFONSO, L: "Servicios públicos y servicios de interés general..." cit., p. 53 .

${ }^{28}$ DE LOS MOZOS TOUYA. I.: "La gestión indirecta de los servicios públicos locales", REAL 291 (2003), p. 755 y ss.
} 
del concepto, aquí pueden perfectamente tener cabida una serie de actividades libres, no asumidas por la Administración. Por tanto, será necesario que esa asunción se produzca expresamente, en los términos del art. 155.2 LCAP, para que pueda producirse su adjudicación en régimen de concesión ${ }^{29}$. Producida la reserva, es evidente que la concesión exigirá en muchos casos una exclusividad "de facto" 30 , aunque cabrá también que se preste en régimen de concurrencia.

- Sin perjuicio de lo anterior, existe ya una reserva efectuada directamente por el legislador, respecto de los servicios obligatorios, en los que, mientras no se declare expresamente el régimen de monopolio, cabe también que la gestión del servicio se lleve a cabo en concurrencia con empresas privadas ${ }^{31}$.

- La liberalización de los servicios públicos locales -que cuenta ya con ejemplos destacables, como el del Real Decreto-Ley 7/1996, de 7 de junio, de liberalización de la prestación de servicios funerarios- tiene por delante un largo camino que recorrer. Pero no hay ninguna razón objetiva que, desde el punto de vista jurídico, pueda oponerse a ella ${ }^{32}$.

\section{LA POSIBLE INCIDENCIA DE UNA FUTURA DIRECTIVA DE CONCESIONES EN EL MODELO ESPAÑOL DE LA CONCE- SIÓN DE SERVICIOS PÚBLICO}

\section{1. ¿Un Derecho administrativo europeo de las concesiones?}

Antes me he referido a los frustrados intentos de la Comisión Europea, a mediados de la década de los noventa, para lograr la aprobación de una Di-

29 Defiende una tesis distinta FERNÁNDEZ GONZÁLEZ, para quien la declaración del art. 85.1 LBRL habilita ya, de por sí, para acordar la gestión indirecta del servicio, "ya que se trata de servicios de competencia de la Administración local... en relación con los cuales se cumple el requisito de la "publicatio" del art. 156.2 LCAP "(hoy, art. 155.2) (Vid. FERNÁNDEZ GONZÁLEZ,FJ.: "La Ley de Contratos de las Administraciones Públicas y el contrato de gestión de servicios públicos en la Administración local”, REALA 268 (1995) p. 874.

${ }^{30}$ Como señala, a mi juicio con razón, DÍAZ-LEMA (Vid. DÍAZ-LEMA, J.M.: Los monopolios locales, Madrid 1994, p . 61). En contra, DE LOS MOZOS, I.: "La gestión indirecta..." cit., p. 757

${ }^{31}$ Vid. en este sentido SOSA WAGNER, F.: La gestión de los servicios públicos locales, $5^{\underline{a}}$ ed., Madrid 2002, p. 45, nota 24 .

${ }^{32}$ Vid. un intento de construir un régimen de autorización reglamentaria, como alternativa al modelo concesional en los servicios locales, en SÁNCHEZ DÍAZ, J.L.: "Los servicios locales de naturaleza económica. Municipalización, concesión y autorización”, REAL 291 (2003), p. 1041-1062. 
rectiva sobre concesiones de servicios públicos (o, más exactamente, de unas normas sobre concesiones de servicios públicos en el seno de la Directiva sobre contratos de servicios) circunstancia en la que, al parecer, tuvo mucho que ver el escaso entusiasmo de las autoridades francesas de la época.

Desde entonces hasta hoy, los planteamientos sobre la incidencia del Derecho comunitario en el concepto del "service public" y, en particular, en el clásico régimen concesional, se han sucedido, con enfoques muy distintos según su origen.

a) Desde el ámbito anglosajón, se subraya que el "service public" es una doctrina legal abstracta, cuyos dogmas centrales han sido desafiados por el proceso de integración europea. El concepto y su principal manifestación, las concesiones -que se ven como mecanismos proteccionistas frente a la competencia, y faltos de la necesaria transparencia- son cuestionados, y se señala que de ser un modelo exportable -dentro y fuera de Europa- se ha convertido en una posición que hay que defender ${ }^{33}$. Los franceses -se dice- quieren retener la configuración de los servicios públicos definidos en términos de servicios de red (agua, electricidad, gas, transporte público y radiodifusión); el Derecho comunitario fuerza a reformar la estructura misma del servicio -multitud de pequeñas concesiones municipales gestionadas por una gran empresa pública monopolista, ausencia de acceso de terceros operadores ${ }^{34}$. La impresión que se desprende de estos y otros trabajos es que, antes o después, el modelo del servicio público y el régimen concesional, cuyo bastión fundamental está en Francia, deberá ceder frente a un modelo comunitario que casa mal con la "ideología" del servicio público.

b) Los defensores del "service public a la française" hablan del "éxito internacional" del modelo, proponen líneas de actuación para su defensa, tales como la promoción de la experiencia francesa a través de los Bancos internacionales de desarrollo "para contrapesar el predominio de las prácticas y referencias anglosajonas", "influir en la cúpula de la Comisión, para la elaboración y negociación sobre las futuras directivas sobre concesiones de servicios" e "in-

33 COLE, Alistair: "The "Service Public" Under Stress", West European Politics, nº 4, octubre 1999, p. 166-183.

${ }^{34}$ BELL, John: "The Concept of Public Service under threat from Europe? An Illustration from Energy Law”, European Public Law, vol. 5, no 2 (1999), p. 189-198. 
fluir en los demás Estados miembros para consolidar los que están próximos a nosotros" (entre los que se cita a España y Portugal) ${ }^{35}$.

c) Desde la Comisión se ha insistido siempre en el respeto del Derecho comunitario por las diferentes formas jurídicas que se regulan en los derechos nacionales, y señaladamente en el caso -quizás por ser el que se siente más amenazado- del régimen francés de la "gestión deleguée", en el que, como es sabido, tienen cabida figuras variopintas, como la concesión, el arrendamiento, la "régie interessée" o la gerencia. "El derecho comunitario -afirmaba en 1996 Jean-Louis Dewost, Director general del servicio jurídico de la Comisión- "no exige en absoluto una supresión o una modificación de estas diversas expresiones de la delegación del servicio público"; tan sólo se pretende, en efecto, neutralizar las distorsiones de la concurrencia que podrían resultar de las diferentes formas conocidas en los derechos nacionales. "El malentendido -añadía- viene de que se ha atribuido a la Comunidad la idea de haber querido crear un derecho administrativo europeo de los contratos, cuando el legislador comunitario ha querido crear un derecho eco$\underline{\text { nómico }}$ con el fin de someter a la concurrencia contratos que representan... el 11 por 100 del producto interior bruto de la Comunidad" 36 .

¿Existe un "derecho administrativo europeo de las concesiones de servicio público? Posiblemente no; pero lo cierto es que algo ha cambiado en estos últimos años. A partir de la bien conocida "Comunicación interpretativa de la Comisión sobre las concesiones en el Derecho comunitario" (2000/C, $121 / 02)^{37}$, se han producido dos nuevos documentos en los que se recogen ya

\footnotetext{
35 MARTINAND, C: "L'influence internationale du concept de gestion deleguée du service public" en el número monográfico sobre La gestion deleguée du service public, Revue Française de Droit administratif no 3 (1997), p. 129-134. Entre nosotros, GONZÁLEZ-VARAS afirma que el modelo base para la aplicación del art. 90.2 del Tratado (hoy, 86.2) debe ser el "service public", y que "es a los Derechos donde no rige esta institución del servicio público a los que corresponde hacer un esfuerzo especial, de aproximación al régimen jurídico del servicio público, si quieren beneficiarse de la exención del artículo 90.2" (GONZÁLEZ-VARAS, S; "El Derecho comunitario ante el servicio público y la competencia”, Gaceta Jurídica de la CEE, junio 1997, p. 17-21).

36 DEWOST, J.L.: "Le point de vue des instances communautaires sur la gestion deleguée", en La gestion deleguée ... cit., p. 93-99.

37 Vid. sobre esta Comunicación los comentarios de MATTERA, A.: "La communication interpretative de la Commission Sur les concessiones de services d'utilité publique: une instrument de transparence et de liberalisation", RDUE nº 2 (2000), p. 259-60; SOSA WAGNER, F.: "Los servicios públicos locales..." cit., p. 194-197; y MEDEIROS, R: "A contrataçao publica nos sectores con regime especial -agua, energía, transportes e telecomunicaçoes”, en La contratación pública en el horizonte de la integración europea, Madrid 2004, p. 153-156.
} 
los conceptos y definiciones de aquella: la Propuesta modificada de Reglamento del Parlamento Europeo y del Consejo sobre la intervención de los Estados miembros en materia de obligaciones de servicio público y adjudicación de contratos de servicio público en el transporte de viajeros por ferrocarril, carretera y vía navegable (COM (2002) 107 final) y el Libro Verde sobre la colaboración público-privada y el Derecho comunitario en materia de contratación pública y concesiones (COM (2004) 327 final).

Conviene advertir, para ser coherente con el hilo conductor de este trabajo, que la Comunicación de la Comisión se refiere tanto a las concesiones de obra pública como a las estrictas concesiones de servicios públicos (a las que aquí todavía se denomina, de forma un tanto ambigua, "concesiones de servicios"). El sustrato común, en ambos casos, es que se trata de "actos imputables al Estado por los que una autoridad pública confía a un tercero -ya sea mediante un acto contractual o mediante un acto unilateral con el consentimiento del tercero- la gestión total o parcial de servicios que normalmente son de su competencia y para los que dicho tercero asume el riesgo de explotación". A partir de aquí, lo que singulariza a la "concesión de servicios" es que en ella la realización de obras -si existe- debe tener carácter accesorio; lo decisivo es "el establecimiento y la explotación del servicio" asumiendo el riesgo del mismo y cobrando una parte significativa de su remuneración al usuario.

Es interesante destacar, ya desde este momento, que la Comunicación incluye expresamente en su ámbito de aplicación la concesión de derechos exclusivos: "las modalidades de concesión de estos derechos exclusivos están sujetas a las normas del Tratado y pueden por tanto entrar en el ámbito de aplicación de la presente Comunicación”.

En definitiva, lo que hace la Comunicación es seleccionar las normas del Tratado -y los principios que, a partir de ellas, ha sentado el Tribunal (sobre todo en relación con los contratos públicos)- que considera aplicables al campo de las concesiones: igualdad de trato, transparencia, proporcionalidad y reconocimiento mutuo.

Una primera plasmación de estos principios se encuentra en la Propuesta de Reglamento, ya citada, en materia de obligaciones de servicio público y adjudicación de contratos de servicio público en el transporte de viajeros por ferrocarril, carretera y vía navegable. La Propuesta se enfrenta con una situación en la que los Estados miembros prestan servicios de transporte público de viajeros de diferentes formas: bien de forma directa, bien de forma indirecta 
mediante empresas bajo control o bien encomendando su prestación a terceros, públicos y privados.

La Propuesta contempla, lógicamente, una serie de normas relativas a la adjudicación de concesiones de servicios públicos de transporte de viajeros, que define mediante una remisión al concepto de concesión establecido por la Comunicación. Serán estas normas, y no las Directivas sobre contratos, las que deberán aplicase en esta materia. Pero la Propuesta considera que la fórmula que ha permitido mayores avances en el acceso al mercado de transporte público -con costes más bajos y mejores servicios- es el modelo que inicialmente denominaba de "competencia regulada" y que, en el texto modificado por la Comisión, se llama "competencia controlada", que se presenta como una "alternativa a la liberalización". Se afirma que "esto puede consistir en la existencia de competencia para la concesión de derechos exclusivos o en la asignación de tareas específicas a operadores de propiedad pública, en un contexto en el que otros operadores pueden también prestar sus servicios, pero en el que todos están obligados por unos requisitos de calidad e integración". Aquí se enlaza con la idea expresada por la Comunicación interpretativa, referente a que la concesión de derechos exclusivos debería someterse a las normas del Tratado y, por tanto, a los principios aplicables a la adjudicación de concesiones de servicios.

Esto tiene como consecuencia que la forma jurídica del "contrato de servicio público" sea común a las concesiones de servicio público y a las obligaciones de servicio público. De ahí que el artículo 5 de la Propuesta imponga la obligación de concluir este tipo de contratos tanto para "el pago de toda compensación económica por el coste de cumplir obligaciones de servicio público", como para "la concesión de todos los derechos exclusivos". La regla general es la licitación, si bien se prevé la posibilidad de adjudicación directa en función del tipo de servicio (ferrocarril ligero o metro) o de la cuantía ${ }^{38}$.

Finalmente, el Libro Verde sobre colaboración público-privada y el derecho comunitario en materia de contratación pública y concesiones (COM (2004) 327 final), es un documento surgido en el contexto de la Estrategia para el mercado anterior 2003-2006 y de la llamada Iniciativa europea de crecimiento. En la parte específica dedicada a la materia de concesiones de servi-

\footnotetext{
${ }^{38}$ Vid. un comentario a esta Propuesta en GONZÁLEZ-VARAS, S.: "Las concesiones ante el Derecho comunitario”, Unión Europea Aranzadi, no 2 (2003), p. 15-17 y, más recientemente, FERNÁNDEZ FARRERES, G.: "Los transportes por carretera y competencia", en el vol. colectivo Transportes y competencia, Madrid 2004, p. 508 y ss.
} 
cios, la Comisión constata una vez más que existe un régimen que se deriva de los artículos 43 y 49 del Tratado, que se ha venido refiriendo hasta ahora a la etapa de adjudicación de la concesión, pero que no implica ninguna coordinación de las legislaciones de los Estados miembros. Esta ausencia de coordinación puede ser un obstáculo para la verdadera apertura comunitaria de las operaciones en cuestión, y de ahí que la Comisión advierta que "podría plantearse proponer una acción legislativa destinada a coordinar los procedimientos de adjudicación de concesiones en la Unión Europea”. Aquí hay ya un paso más respecto de la Comunicación interpretativa, que se limitó a identificar los preceptos del Tratado aplicables a las concesiones. Pero además, el Libro Verde se plantea también las exigencias de esos preceptos en la ejecución del contrato de concesión: "las condiciones de ejecución -señala- no pueden tener un efecto discriminatorio, directo ni indirecto, ni obstaculizar de manera injustificada la libre prestación de servicios o la libertad de establecimiento". Esto tiene consecuencias respecto de temas tales como las modificaciones de la concesión, prórrogas, obras o servicios complementarios, etc.

Aun es pronto para saber si estas iniciativas de la Comisión saldrán adelante, o quedarán de nuevo frustradas. En todo caso, habrán servido para recordar que son aplicables a las concesiones los principios de transparencia, igualdad de trato, proporcionalidad y reconocimiento mutuo, lo que previsiblemente llevará al Tribunal a aplicarlas, en la línea de su Sentencia Telaustria (C-324/98), que afirmó que "[la] obligación de transparencia que recae sobre la entidad adjudicadora consiste en garantizar, en beneficio de todo licitador potencial, una publicidad adecuada que permita abrir a la competencia el mercado de servicios y controlar la imparcialidad de los procedimientos de adjudicación".

\section{Consecuencias para el ordenamiento español.}

Conviene comenzar advirtiendo que muchas de las exigencias contenidas en los documentos comunitarios citados, se hallan ya plasmadas en el Derecho español, tanto a nivel general como sectorial. El Libro Verde sobre colaboración público-privada observa que "muy pocos Estado miembros han querido dotarse de legislación interna destinada a regular de manera general y detallada la etapa de adjudicación de concesiones de obras y servicios", pero en nota a pie de página cita a España como uno de los que sí lo ha hecho.

No obstante, creo que una futura Directiva de concesiones que recogiese los criterios de los documentos en cuestión, podría plantear la necesidad de revisar y adaptar algunos puntos concretos: 
a) Criterios de adjudicación que pueden conllevar efectos discriminatorios. Así, el art. 74.2 de la Ley 16/1987, de 30 de julio, de Ordenación de Transportes Terrestres, establece que "en el supuesto de que la oferta, que en su caso hubiese presentado el anterior concesionario, mereciera similar valoración que otra u otras de las presentadas, deberá tener preferencia sobre las mismas, siempre que la prestación del servicio se haya realizado en condiciones adecuadas, en los términos que reglamentariamente se determinen".

b) Replanteamiento del plazo de duración de muchas concesiones, en las que la legislación contempla períodos máximos muy amplios, que exceden con mucho del tiempo necesario para amortizar la inversión (cincuenta años los que comprendan la ejecución de obras -se entiende que accesorias, porque sino estaríamos ante una concesión de obras- y la explotación de un servicio público, o veinticinco años los que comprendan la explotación de un servicio público no relacionado con la prestación de servicios sanitarios).

c) Regulación más precisa de los supuestos y condiciones en que proceden las prórrogas; el art. 157 LCAP se limita a mencionarlas y en la legislación local el Reglamento de Servicios de las Corporaciones Locales ni siquiera las cita, aunque alude a la posibilidad de que la Corporación concedente pueda modificar el servicio por razones de interés público, mencionando el "tiempo" de las prestaciones (art. 127.1.1 ${ }^{\circ}$ ); y el art. 11 de la Ley reguladora de la televisión privada contempla una prórroga sucesiva e indefinida, en manos del Gobierno, "por períodos iguales" sin sometimiento a ningún tipo de criterio o requisito, más allá del "sic volo, sic iubeo" gubernamental. La prórroga debe limitarse a los supuestos en que sea necesaria para restablecer el equilibrio financiero de la concesión, alterado por medidas ordenadas por la Administración o por circunstancias imprevisibles, sin que puedan aceptarse genéricas razones de "interés público".

d) Eliminación del subterfugio de la conversión de la concesión en empresa mixta, una vez llegado el fin del plazo concesional, como fórmula para asegurar la prolongación del disfrute de los derechos de exclusiva sin someterse a una nueva licitación (caso en el que se encuentran muchas empresas mixtas locales de abastecimiento de aguas, en virtud de una interpretación bastante discutible del art. $104.3^{\circ}$ del Reglamento de Servicios, que se refiere a la creación de una empresa mixta por "convenio" con una empresa ya existente) ${ }^{39}$.

\footnotetext{
${ }^{39}$ Ya hace tiempo señalaba ALBI que "en la práctica ello es frecuente; muy frecuente ... la Administración se aprovecha de una coyuntura favorable para transformar una concesión en una empresa mixta ..." (ALBI, F.: Tratado de los modos de gestión de las Corporaciones Locales, Madrid 1960, p. 411).
} 
e) En el caso del servicio universal y las obligaciones de servicio público, replanteamiento de las formas de asignación de éstos, promoviendo -cuando sea posible- la licitación y la forma contractual, en la que se determinen con claridad los derechos y obligaciones del adjudicatario. 